\title{
Cosmopolitan Sentiment: Politics, Charity, and Global Poverty
}

\author{
Joshua Hobbs $^{1}$
}

Published online: 29 July 2020

(c) The Author(s) 2020

\begin{abstract}
Duties to address global poverty face a motivation gap. We have good reasons for acting yet we do not, at least consistently. A 'sentimental education', featuring literature and journalism detailing the lives of distant others has been suggested as a promising means by which to close this gap (Nussbaum in Upheavals of Thought: The Intelligence of Emotions, CUP, Cambridge, 2001; Rorty in Truth and Progress: Philosophical Papers, vol. 3, CUP, Cambridge, 1998). Although sympathetic to this project, I argue that it is too heavily wed to a charitable model of our duties to address global poverty - understood as requiring we sacrifice a certain portion of our income. However, political action, aimed at altering institutions at both a global and a local level is likely to be necessary in order to provide effective long-term solutions to poverty globally. To rectify this, the article develops an alternative dialogical account of sentimental education, suitable for motivating support for political action to address global poverty.
\end{abstract}

Keywords Sentiment $\cdot$ Cosmopolitanism $\cdot$ Motivation $\cdot$ Global justice

\section{Introduction}

Duties to address global poverty face a motivation gap (Lichtenberg 2014; Long 2009). We have good reasons for acting yet we do not, at least not consistently. A 'sentimental education', in which literature and journalism detailing the lives of distant others serves to encourage greater affective identification with these individuals (Nussbaum 2001; Rorty 1998), has been suggested as a promising means by which to close this gap.

Although sympathetic to this project, this article argues that it is too heavily wedded to a charitable model of our duties to address global poverty, understood as

Joshua Hobbs

j.j.hobbs@leeds.ac.uk

1 Interdisciplinary Ethics Applied, University of Leeds, 17 Blenheim Terrace, Leeds LS2 9JT, UK 
requiring we sacrifice a certain portion of our income. However, political action, aimed at altering institutions at both a global and a local level is likely to be necessary in order to provide effective long-term solutions to poverty globally. I then go on to develop an alternative account of sentimental education, suitable for motivating support for political action to address global poverty.

The argument is divided into three sections. Section one outlines the traditional model of sentimental education, and argues that it faces two key shortcomings as a means to motivate support for political strategies to address global poverty. Firstly, it presents individuals facing poverty globally in a manner that obscures their capacity for agency; however, political strategies to address global poverty rely on a picture of these individuals as capable agents. Secondly, this model leads to affective connections with distant others that are highly abstract in nature. Motivating effective political solutions requires the development of more specific affective ties.

Drawing on the arguments advanced in section one, section two develops an alternative model of sentimental education as dialogue, conducive to motivating political action. As dialogue may not always be feasible in practice, dialogue operates here as a guiding ideal rather than a strict requirement. I argue that processes of dialogue will typically be mediated in practice, through the presence of third parties, such as journalists or NGOs, and examine what appropriate mediation entails.

Section three applies this dialogic model of sentimental education to four sites of sentimental education: (i) the media, (ii) NGO practices, (iii) formal education, and (vi) the international trade union movement. In doing so, I highlight examples of good practice, which serve to demonstrate that the account offered here is not only practically feasible, it is a reality in action.

\section{Section One: Political Solutions, Agency, and Abstraction}

\section{Political and Charitable Approaches}

Within liberal political theory there is some consensus that individuals in the richer communities of the world ought to act to address global poverty. In determining what action this obligation entails, theorists have offered two broad approaches.

The first approach, as exemplified by Peter Singer, argues that the relatively affluent ought to divert a sizable portion of their income to the more effective aid organisations. Singer offers a number of examples of such organisations, but he primarily focuses on those addressing infectious diseases and delivering supplies in the aftermath of humanitarian crises (Singer 2010, pp. 81-105). The second approach, associated with the work of Thomas Pogge, argues that the globally affluent ought to pressure their own governments to support the reform of global institutions that act to systematically disadvantage less affluent nations (Pogge 2002). In keeping with the current literature (Kuper 2002; Langlois 2008) I will refer to these two approaches as charitable and political accounts of duties to reduce global poverty. To avoid potential misunderstandings, the use of the term 'charitable' here in no way implies that proponents of the former approach take donations towards aid organisations to be supererogatory. 
In drawing a distinction between political and charitable accounts of duties to reduce global poverty previous discussions have highlighted the following features: (i) charitable accounts tend to emphasise financial donations in contrast to political activism; (ii) political accounts typically focus on long-term solutions to chronic poverty, whereas charitable accounts primarily focus on alleviating immediate need (Singer 1972). At the level of framing the following two further distinctions can be drawn: (iii) charitable relationships are traditionally understood to involve a significant power differential between the helper and the helped, with agency primarily lying with the former. As Kirk observes, 'charity...rests on the interaction between a powerful giver-be that an individual or a nation - and a grateful receiver. In this paradigm, agency lies almost exclusively with the powerful givers' (2012, p. 248). (iv) Political approaches tend to emphasise the agent's own causal complicity in global poverty, for example through benefiting from or supporting an unjust international order that is at least partially responsible for much poverty globally (Pogge 2002). It is important to note that for each of these features this is a question of emphasis rather than a strict binary. However, I take these distinctions to capture important differences between charitable and political accounts, and, for the purposes of this paper, employ a family resemblance view of the two approaches based on the features outlined.

\section{Motivating Cosmopolitanism}

There is a significant and nuanced literature on strategies to develop more cosmopolitan orientations, to which I cannot do full justice here. Advocates of institutional solutions argue that a lack of motivation to address global poverty and other injustices can be largely attributed to a lack of robust global institutions (Ulas 2017; Weinstock 2009). These theorists suggest that collective membership of global institutions could, over time, lead to the formation of a robust sense of community with distant others-motivating individuals to live up to their cosmopolitan commitments (Ulas 2017). Statist cosmopolitans advocate utilising the machinery of the state to create more cosmopolitan identifications amongst the citizenry (Ypi 2008). Although sceptical concerning the broader cosmopolitan project, Lenard (2012) argues that the resources employed by nation states to inculcate robust national identities might be fruitfully applied to the task of creating cosmopolitan identifications. Avoiding a binary understanding of national versus cosmopolitan identity, Erskine's account of 'embedded cosmopolitanism' (2008) has explored multiple and overlapping sources of identification that may be able to motivate individuals to act in a more cosmopolitan manner without identifying as a cosmopolitan as such. Proponents of 'thick cosmopolitanism' recommend highlighting causal relationships between individuals in more affluent countries and distant others (Lawford-Smith 2010; Linklater 2007; Dobson 2006). This strategy combines Pogge's (2002) argument that individuals in more affluent countries are causally responsible for harming the global poor, through the collective imposition of unfair trading terms at the global level, with the psychological assumption that we feel greater moral urgency to rectify harms caused by our actions, than to address similar harms for which we 
are not causally responsible (Lawford-Smith 2010). Other theorists have rightly drawn attention to the other-directed nature of this debate, arguing that the task of motivating cosmopolitan behaviour need not purely rest on duty or fellow-feeling but can be in part supported by citizen's rational self-interest (Bufacchi 2005), for example, through reducing the risk of global pandemics or unrest fostered by severe poverty (Weinstock 2009).

The sentimental cosmopolitan approach, which is the focus of this article, argues that limited action to address global poverty and other global injustices can be explained by a lack of affective concern for distant others on the part of individuals in more affluent countries. To address this, sentimental cosmopolitans recommend a process of 'sentimental education' where exposure to sympathetic portrayals of distant others in media and narrative art serve to develop the affective connections necessary for cosmopolitan arguments to motivate. In doing so, sentimental cosmopolitanism foregrounds the (plausible) assumption that affect is central to moral motivation (Green et al. 2001; Izard and Ackerman 2000). Finally, it should be noted that these approaches are not competitors, and that the complex task of motivating cosmopolitan action likely requires employing a variety of these strategies in tandem.

\section{The Traditional Model of Sentimental Education}

The concept of a 'sentimental education' has been developed in recent sentimental cosmopolitan scholarship (Woods 2012; Long 2009), but has two primary sources. Richard Rorty's (1998) argument that journalism and literature encouraging sentimental identification with groups previously seen as other have played a key role in encouraging respect for human rights globally, and Martha Nussbaum's (2001) account of the role of art and literature within formal education as a means to encourage the extension of compassion beyond national borders. Although these two accounts differ in some respects, they share a number of important features. Drawing on the commonalities between these two accounts I will offer a brief sketch of what cosmopolitan sentimental education is typically understood to entail. The picture provided here is not intended to be exhaustive, but to serve as a reference point for the discussion which follows.

The basic claim that underlies the idea of a sentimental education is that exposure to representations of the lives of distant others, in narrative art and print and television journalism, can lead to increased sentimental identification with those facing similar hardships. This increased sentimental identification can in turn motivate a greater propensity to undertake action in support of these individuals. From this basic claim I wish to draw out three features: (i) the nature of the sentimental connection, (ii) how this is achieved, and (iii) the end towards which this connection is put.

The nature of the connection. Both accounts are concerned that those in positions of relative power develop kinder feelings towards marginalised others. Rorty primarily focuses on the extension of sympathy to those suffering from human rights abuses (1998), whereas Nussbaum's account advocates developing compassion for 
the sufferings of individuals beyond national borders (1993). We can note two commonalities here. First, both accounts focus on developing a unidirectional sentimental connection on the part of those in positions of relative power, for those suffering injustices. Second, on both accounts, attention is directed towards the suffering other, with notions of responsibility for their suffering playing a minimal role.

How the connection is achieved. Both authors share the conviction that representations of the lives of distant others, encountered in narrative art and within the media, are the primary means by which to encourage this extension of affective concern. However, there is a difference of emphasis. Rorty's account focuses on the role of journalism, and what he terms 'middlebrow art forms', such as popular novels, and television shows (1991, pp. 66-85) encountered in day-to-day life. Nussbaum does not deny that these mediums are important, but argues that their content is especially vulnerable to being determined by market pressure (2001, p. 435). Instead, Nussbaum's account focuses on the role of narrative art forms, especially literature, encountered during formal education, as a means of promoting sentimental concern (2001, pp. 425-433).

It is important to note three things here. First, encounters with representations of the lives of distant others operate in place of actual interaction with these others. This is a point to which I return below. Second, in this process encounters with depictions of the lives of distant others are necessarily mediated to some degree, for example through the presence of journalists or educators (Woods 2012, pp. 41-44). Third, on both accounts, images of suffering others serve as the primary means by which to provoke increased sentimental concern. Nussbaum's account of the structure of compassion makes it clear that she considers this emotion to arise in response to suffering, requiring that an agent must 'consider the suffering of another as a significant part of his or her own scheme of goals and ends', and take this suffering to be both serious, and undeserved (2001, p. 319). Similarly, Rorty suggests that sentimental education requires people to 'turn their eyes toward the people who are getting hurt, [and] notice the details of the pain being suffered' (1998, p. 80).

Intended action. Although both authors offer a relatively incomplete picture of the action they hope a sentimental education to motivate, neither offers an explicitly political model of this action. For Nussbaum, global poverty is one of a number of cosmopolitan injustices that a sentimental education can motivate action to address (1996, pp. 3-17). The focus of Rorty's 1993 Amnesty lecture is on reducing negative human rights violations (traditionally understood); however, in other work Rorty (1991) suggests a sentimental education can motivate action to address global poverty, but is relatively silent on what action this entails. Although neither author rules out political action to address global poverty, both operate with a primarily charitable model of the action required. Political responses to global poverty aim to identify institutional causes of global poverty and promote alternative institutional arrangements; however, there is scant attention to the institutional causes of global poverty, and identifying responsible parties, on either Rorty's or Nussbaum's account. Although responsibility features on Nussbaum's model insofar as for compassion to be appropriate an agent's suffering must be undeserved, Nussbaum does not take the further step of identifying responsible parties, or institutional causes of this suffering. Rorty's account shares this lack of emphasis on identifying those 
responsible for suffering. As Woods observes, on Rorty's account 'sympathy floats free from responsibility, suffering exists almost spontaneously. Agents encounter suffering independent of causal factors and respond to it without questioning its roots' (2009, pp. 60-61).

I want to suggest that the traditional model of sentimental education faces two key shortcomings as a means to motivate support for political action to address global poverty. (i) The means by which the traditional model aims to bring about increased sentimental identification with individuals facing global poverty risks obscuring the agency of these individuals. Woods (2012) and O'Neill (2000) have highlighted the adverse effects obscuring the agency of individuals facing global poverty has on motivating support for attempts to address global poverty; however, here I make the claim that this poses a particular problem for political approaches. (ii) The use of representations of distant others to bring about an unidirectional increase in affective concern on the part of the globally affluent, lends itself to the development of an excessively abstracted form of affective identification. However, political action to reduce global poverty requires the cultivation of a more robust affective relationship.

\section{Concerns for the Traditional Model}

\section{i. Agency and Political Action}

Political action and perceptions of agency. The claim that support for political strategies to reduce global poverty is especially linked to perceiving individuals facing global poverty as active agents may, on the face of it, appear puzzling. However, a link between perceptions of particular others as active agents, and a willingness to come to the aid of these others, is a feature of much of the theoretical literature on the concept of solidarity (Straehle 2010; Gould 2007). Solidarity, understood as a particular kind of affective relationship binding individuals or groups, and particularly conducive to political action, is thought to differ in kind from the affective relationship underlying charitable donation. There is a danger of begging the question at issue here, and drawing an overly sharp theoretical distinction between a political solidarity, and an apolitical pity or compassion, where whichever affective relationships motivate support for political action necessarily fall into the former category, and those motivating charitable donation, the latter. I do not wish to claim that such a sharp distinction is tenable, or that those moved to act by solidaristic feelings will not sometimes find that their aims are best served by charitable donation, or vice versa. Nevertheless, I do wish to argue that a form of affective concern, which recognises the agency of its subject, may be particularly conducive to motivating political strategies to reduce global poverty.

An initial route links agency to an expectation of reciprocity, or mutual aid, thought to differentiate a robust disposition of solidarity, from feelings of pity or compassion. As Carol Gould notes, 'solidarity, rather than pity or compassion, is thought to presuppose some degree of equality between agents, and an expectation of reciprocity' (2007, p. 154). This expectation of reciprocity or mutual aid necessarily requires that we see those we stand in a solidaristic relationship with as agents, capable of returning the favour, either now, or at some future time (Woods 
2012, p. 41). Accordingly, solidarity may be more motivationally efficacious than compassion as it includes a weak prudential incentive. Political solutions to global poverty, thought to place particular motivational burdens on individuals, can take advantage of these additional motivational resources. However, this route faces two serious concerns. First, reciprocity is unlikely in the case of distant others, as 'these others may not be aware of one's actions in solidarity with them' (Gould 2007, p. 154). Second, this looks especially untenable in the case of individuals facing global poverty, as their ability to assist is necessarily limited.

Even if reciprocity provides little additional motivational resources in this context, perceiving distant others as active agents may lead to more robust forms of sentimental identification. This is because a capacity for agency is typically an important feature in the self-understandings of the globally affluent (Haldane 2008), ${ }^{1}$ and perceiving distant others as fellow agents, rather than just passive victims, can plausibly provide an additional source of identification. However, fully pursuing this line of argument requires empirical research beyond the scope of the paper; therefore, I will instead offer two reasons why recognising individuals facing global poverty as active agents is especially important for motivating support for political strategies to address global poverty.

First, political strategies to address global poverty that aim to alter global institutions thought to be responsible for causing, or entrenching, global poverty, such as unfair trade rules (Pogge 2002, pp. 169-172) presuppose the agency of individuals facing global poverty. This is because taking advantage of alternative institutional set-ups requires individuals facing global poverty to engage in complex practices, such as international trade, which necessarily require a high level of agency (Woods 2012; O'Neill 2000). Where the global poor are not viewed as purposive agents such strategies will appear implausible. This is compatible with the claim that the injustice of current global institutions is precisely that they undermine people's agency, as these individuals' agency would no longer be undermined by alternative institutional arrangements which allowed them opportunities to engage in purposive activities. Moreover, all attempts to address global poverty presuppose some level of agency on the part of those facing global poverty. However, support for financial donations to provide food, or immunisation programmes, is compatible with a view of these individuals that attributes them a more minimal degree of agency.

Second, political strategies to address global poverty often require engaging with particular individuals facing global poverty as active agents. This can either take the form of working together to achieve a solution, such as supporting the political struggles of those facing poverty globally, or individuals in more affluent countries may act alone, but enter into processes of dialogue to determine what action it is appropriate for outsiders to take. In both cases Carol Gould's requirement of 'deference to those in need' is operative, where it is normatively appropriate to consult

\footnotetext{
1 The centrality of the capacity for agency in the self-understandings of the globally affluent, at least those within the Western liberal tradition, can be seen in the literature on the ethics of care, which aims to provide a corrective to this picture by emphasising our shared dependency and vulnerability to harm (Haldane 2008).
} 
those facing a particular injustice in determining solutions, and practically sensible, as these individuals are likely to have relevant experiential knowledge of the situation (2007, p. 157). This is significant, as deference to the judgements of individuals facing global poverty, presupposes, not only a particularly high degree of agency on their part, but respect for this agency. These strategies therefore are not only incompatible with a picture of individuals facing global poverty that obscures their agency, but also with considering these individuals to be purposive agents with a lesser capacity for agency than individuals in more affluent countries.

Sentimental education and agency. I have argued elsewhere that strategies of sentimental education that rely on portraying individuals facing global poverty as suffering and vulnerable in order to provoke affective concern can have adverse motivational effects, increasing perceptions of distance between affluent individuals and individuals facing global poverty. I will not fully rehearse these arguments here, but instead restate the general claim, and note two further ways in which the traditional model of sentimental education can serve to obscure the agency of the individuals for whom the process is intended to generate reactions of empathy and compassion.

Strategies of sentimental education that attempt to increase affective concern for individuals facing global poverty by emphasising their neediness, suffering, and vulnerability, are central to the traditional model of sentimental education, and are a familiar feature of the campaigning literature employed by NGOs working in international poverty relief (Woods 2012, p. 41). However, if individuals facing global poverty primarily appear to persons in affluent countries in this manner, it can undermine perceptions of these individuals as capable agents, a quality which typically features heavily in the self-understandings of individuals in affluent countries (Haldane 2008). To be clear, the claim here is not that 'they' are vulnerable and 'we' are not, or that 'we' are 'capable agents' and they are not. What I am suggesting is that that such strategies present a misleading picture that both obscures the agency of distant others and the vulnerability of the affluent. ${ }^{2}$ Due to the links between political strategies to address global poverty and perceptions of individuals facing global poverty as active agents discussed above, this poses a particular problem for motivating political action.

Where sentimental education focuses on cultivating affective concern for those suffering as a result of global injustices without also attending to questions of responsibility, particularly at the institutional level, the agency of individuals facing global poverty may be further obscured. When global poverty is encountered absent attention to its political causes we are offered an incomplete picture, of individuals unable to secure the means to survive, rather than capable agents constrained by unjust institutions. Here, perceptions of agency are compromised in two ways. First, poverty may be interpreted as resulting from a lack of ability of the part of individuals facing global poverty, rather than due to institutional factors at a national and global level. Second, insofar as a capacity for agency is compromised by the effects

\footnotetext{
${ }^{2}$ I use these terms as they are prevalent in the literature, while acknowledging that such language serves to reinforce this picture.
} 
of global poverty, this diminished agency may be taken for the norm, rather than as a temporary situation.

A second issue is that charity is the current paradigm through which global poverty is typically viewed by publics in more affluent countries. This is corroborated by empirical studies by Kirk et al. (2012). Here, there are two concerns. First, where sentimental education does not explicitly focus on political causes and solutions to global poverty, it will plausibly be interpreted within the dominant paradigm, as it makes no attempt to challenge or question this approach. Second, the emphasis within the traditional model of sentimental education on encouraging reactions of sympathy or compassion may lend itself to interpretation within a charitable paradigm, due to the lack of attention to responsibility for injustice in the structure of these sentiments (Hobbs 2019). Moreover, as a number of theorists have argued (Lichtenberg 2014, pp. 180-184; Woods 2012, p. 42), charitable relationships are traditionally understood to involve a significant power differential between a powerful giver and a beneficiary. This relationship can further obscure the agency of individuals facing global poverty. As Kirk notes, 'most conceive of aid and development as being acts of charity. Charity, in turn, rests on the interaction between a powerful giver-be that an individual or a nation-and a grateful receiver. In this paradigm, agency lies almost exclusively with the powerful givers' (2012, p. 248).

\section{ii. Abstraction}

Sentimental cosmopolitans propose that encounters with depictions of the lives of distant others in narrative art or news media will, in the right circumstances, lead to affective concern for abstract representations of individuals facing global poverty or the subjects of sympathetic news coverage, from which we are then encouraged to generalise to like cases. In either instance, abstraction plausibly compromises the motivational efficaciousness of the sentimental connection. The first issue is with the process of generalisation itself, as the motivational efficaciousness of affective concern for specific individuals (real or imagined) facing global poverty will likely be compromised as we generalise to other cases. This is a problem for all attempts to move from affective connections to particular others to connections to groups to which these individuals are taken to belong (Bartky 2002). However, where particular representations serve to cultivate connections with specific groups of similarly situated individuals, rather than to a generalised 'distant other' or 'global poor', these connections are likely to be both more robust and better able to motivate informed action. Knowledge of the specifics of others' situations is only possible at this level. This knowledge is important, not only for identifying effective solutions, but also for developing sufficiently robust affective relationships, as in order to care for others we plausibly need to know something about their actual situation. As Woods notes 'the motivational gap in cosmopolitan thought proceeds in part from an epistemic one' (2012, p. 91). A generalised concern looks both too thin to motivate sustained action and prone to motivating action that is ill-informed.

A second issue concerns the feature, or features, that serve as the basis for generalisation from a particular sentimental story to other cases. Generalisation based on shared poverty can undermine perceptions of the individuals concerned as capable agents. Here, the many different causes and manifestations of global poverty are 
ignored, and instead what is identified is a shared form of suffering, which is not interrogated to address questions of responsibility or blame. Rather than attention to specifics, and the attendant level of complexity, this strategy encourages an image of a single body, "[T]he poor" [who] are understood as an undifferentiated group without intrinsic strength, often referred to through the shorthand of "Africa," where nothing ever changes' (Kirk 2012, p. 248).

\section{Section Two: Sentimental Education Reconceived}

Having outlined the shortcomings of the traditional model of sentimental education as a means to motivate political action to address global poverty, I now offer an alternative model suitable for the task. The model presented here is dialogic, focusing on the development of two-way ties between persons in affluent countries and particular groups or individuals facing global poverty. ${ }^{3}$ This model draws on Carol Gould's (2007) theorisation of 'transnational solidarities', as solidaristic ties linking particular groups and individuals across borders, through the connections offered by globalisation. However, it differs from Gould's account in four key respects: (i) this account is tailored to the specific case of global poverty, and the attendant problems this brings for dialogue; (ii) the focus of the discussion here is applied, and concerned with what dialogue entails in practice; (iii) dialogue operates on my account as a guiding ideal, rather than a strict requirement; and (iv) I argue that dialogue will typically rely on the presence of mediators.

\section{A Dialogic Model}

Where sentimental education proceeds through processes of dialogue rather than through depictions of the lives of others in journalism or narrative art, this offers four advantages. First, dialogue with particular individuals and groups can lead to more robust affective ties. There is some consensus in the psychological literature that affective ties tend to be more robust when they have individuals or small groups as their object (Slovic 2007; Jenni and Lowenstein 1997). Moreover, relationships based on interaction are more likely to involve an accurate picture of the other, than those based on representations alone. Where affective connections are based on an inaccurate picture, further interaction can serve to undermine these ties (Brehm 1966). As discussed above, theorists of solidarity suggest affective relationships that include a condition of reciprocity are typically more robust. Insofar as this is correct, processes of dialogue can lead to more robust affective ties, as they feature an (admittedly weak) form of reciprocity through the process of discussion. As Gould notes, dialogue is 'reciprocal to the degree that interlocutors are ready to learn from others' (2007, p. 188). Second, dialogue is conducive to motivating effective political action, as individuals facing particular instances of poverty globally

\footnotetext{
${ }_{3}^{3}$ Dialogue, as distinct from interaction, involves the use of language.
} 
will typically have an informed perspective on potential solutions. Although individuals within these groups may have conflicting interests, this is a concern for any attempt to address global poverty, with a failure to consult in determining solutions also advantaging certain groups.

Third, processes of dialogue with individuals facing poverty globally are appropriate in determining what action (if any) ought to be taken by persons in more affluent countries. As Gould suggests, a practice of deference to those in need in determining courses of action is normatively appropriate and can lessen concerns over action to reduce global poverty functioning as a neo-imperialist project (2007, p. 157). Finally, processes of dialogue will typically present individuals facing poverty globally in a manner that highlights their capacity for agency, as their agency is demonstrated through participation in dialogue.

Despite dialogue offering a number of advantages for motivating political action to address global poverty, it may be objected that it is not workable in practice, as conditions of severe poverty render dialogue highly difficult. Severe poverty can serve as a barrier to participation in many activities, and may limit access to the infrastructure necessary to facilitate processes of dialogue, such as communication technologies. Moreover, separate from its practical feasibility, processes of dialogue between affluent individuals and individuals facing poverty globally face normative concerns over the complex power relationships at play in these interactions.

Although conditions of severe poverty do make dialogue difficult, this concern can be easily overstated. There are two separate issues here, the effects of extreme poverty rendering individuals unable to participate in processes of dialogue, and limited access to technologies necessary to facilitate dialogue. In the first instance, a picture of global poverty informed by a 'Live-Aid' model (Kirk 2012, p. 254) depicting individuals facing global poverty in positions of extreme vulnerability brought about by drought, famine, and disease, can mislead us over the (in)feasibility of dialogue. While it is implausible to expect dialogue to occur in these conditions, as Collier notes, many of the globally poorest live in conditions that render them highly vulnerable to these sufferings, rather than being presently affected by them (Collier 2007). When environmental or political conditions alter, these individuals are especially vulnerable. Accordingly, dialogue is possible in principle.

The second concern is more serious, as for dialogue to regularly occur in practice, it will typically need to be facilitated by communication technologies. Access to the relevant technologies will vary between different cases of severe poverty worldwide, and between the technologies in question. Sub-Saharan Africa for example, has some of the lowest rates of Internet availability worldwide, although Internet access is growing rapidly and mobile phone use is widespread (ITU 2015). In contrast, in India, which contains more of the world's very poorest individuals than Africa (UN 2016, p. 218), Internet access is more readily available (Real Time Statistics Project 2017). The availability of communication technologies will depend in part on whether the necessary infrastructure is available, which will in turn depend on the quality and stability of governance at a national level, itself a significant factor in global poverty (Collier 2007). However, as the examples of Sub-Saharan Africa and India show, severe poverty occurs globally in very different contexts, and the extent to which communication technologies are available varies. 
Although actual dialogue between individuals facing poverty globally, and individuals in more affluent countries will not always be possible in practice, dialogue can still operate as a guiding ideal, with journalism or narrative art created by individuals facing poverty globally serving as a form of second order inclusion of the voices of distant others (Cabrera 2010), approximating a process of dialogue where actual dialogue is not presently feasible. In such cases, these mediums serve as a temporary, and less than ideal, substitute for actual dialogue (either in person or through communication technologies). Where dialogue is not possible for technological reasons, these forms of inclusion can help motivate support for action to create the infrastructure necessary to facilitate future dialogue. This differs from Nussbaum's (2001, p. 434) and Rorty's (1991, p. 60) accounts of sentimental education which actively prioritise literature and narrative respectively over actual dialogue as the ideal methods to encourage perspective-taking and engender sympathy.

Processes of dialogue between individuals in affluent countries and individuals facing poverty globally can occur either through meetings in person or via communication technologies. The former strategy is illustrated by Sibyl Schwarzenbach's proposal that young people from affluent communities undergo a programme of 'international civic service', travelling to countries where severe poverty is prevalent and assisting with everyday tasks, such as agricultural labour (2009, p. 271). This strategy faces two significant concerns. First, as international travel is expensive and requires the ability to take time out from other responsibilities, this privileges more wealthy members of affluent societies. Second, these interactions foist complex power relationships on individuals and communities facing poverty globally (Woods 2012). The first concern is lessened where interactions are facilitated through formal education or trade unions, as funding can be supplied by the organisation in question. However, involving the more privileged members of affluent societies in processes of sentimental education may actually offer an advantage, as this privilege can translate into a greater ability to effect change, although this may not be a palatable thought. As Rorty notes, the suggestion that 'we shall have to wait for the strong to turn their piggy little eyes to the suffering of the weak, slowly opening up their dried-up little hearts' is something we typically resent (1998, p. 182).

The second concern is more significant. However, no strategies to address global poverty requiring action by the affluent can avoid these power relationships entirely. There is a necessary trade-off here, as deepening levels of interaction may entrench these power relationships, but can also serve to deepen affective connections to individuals facing poverty globally, and encourage recognition of these individuals as capable agents. This highlights the need for dialogue to form part of a broader critical process of sentimental education, where attention is paid to the political causes of global poverty, allowing individuals engaged in dialogue to contextualise these interactions. Underlying differences in relative wealth and power between affluent individuals and individuals facing poverty globally cannot be altered without a change in one, or both, groups' concrete situations. However, attention to the political causes of global poverty, including the agent's own causal complicity in global poverty (where appropriate), can help minimise power relationships deriving from a charitable model of these interactions, featuring a blameless donor and a grateful recipient. None of this is to suggest that such schemes are unproblematic and, where 
language barriers exist, even these direct interactions will be mediated in practice through the presence of translators. Financial cost and logistics also prevent these schemes from directly targeting large numbers of people. However, the experiences of participants in these schemes can be sensitively incorporated into more traditional forms of sentimental education, such as classroom-based learning, as a means to inform students and arouse their curiosity (Cabrera 2010, p. 252), ideally with oversight from the individuals featured.

Communication technologies offer a means by which processes of dialogue can include greater numbers of people. Although access to the relevant technologies can represent a practical obstacle in some cases (as discussed), this can be overcomerendering future dialogue possible. In practice, such processes of dialogue are already occurring through the Internet. The Guardian's Katine village development project (discussed below) offers an excellent example, featuring blogs and webchats by villagers (Collender 2014). These types of projects can involve larger numbers of people at significantly less cost than face-to-face interactions, can include conditions of anonymity where appropriate, and do not place undue burdens on communities through the hosting of volunteers.

As noted above, In addition to actual dialogue, or where dialogue is not feasible, strategies of sentimental education can employ materials authored by individuals facing poverty globally, depicting their own lives and circumstances. As Cabrera observes, such materials can function as a 'potentially significant form of secondary inclusion in dialogue' (2010, p. 249). This allows individuals facing global poverty to take an active role in strategies of sentimental education, and, where this authorship is made clear, encourages perceptions of these individuals as capable agents. As people are typically well-placed to offer accurate portrays of their own lives and circumstances, these accounts can also inform effective strategies to address particular instances of poverty globally.

\section{Mediation}

I have argued that strategies of sentimental education ought to include actual dialogue where possible, and aim to approximate a dialogical process where dialogue is not feasible. However, there are practical reasons why these processes will typically be mediated in practice. Many face-to-face interactions will encounter language barriers, requiring translators for effective communication. Dialogue through communication technologies also faces language barriers, and typically requires hosting platforms such as websites. Literature and journalism produced by individuals facing poverty globally may also require translating and distributing through news agencies or publishers in order to reach large numbers of people. When featured in formal education, these materials will be further mediated through the presence of educators. What these examples suggest is not only that avoiding mediation is difficult in practice, but that a number of diverse processes fall under the concept of mediation, each bringing different potential challenges and benefits.

Strategies of mediation within processes of sentimental education can be divided into three levels. The first level of mediation concerns creating content; for example, 
authoring journalistic accounts, or producing images or video. This level ought to be minimised where possible through the use of materials created by individuals facing particular instances of poverty globally, or through dialogue in person or via communication technologies. Although skill in operating technologies, such as video or photographic equipment, can offer practical advantages here, these can be factored in at the second level of mediation.

The second level of mediation concerns refining content, or rendering it more accessible. This is typified by processes of editing or translating. There are practical reasons why this step cannot always be skipped, especially where language barriers exist. As long as interference at this stage is minimal it poses no serious concerns, although heavily editing accounts can serve to impede dialogue. Insofar as editorial processes involve selecting or rejecting particular images or accounts, this level of mediation can play a more significant role in determining how individuals facing poverty globally are portrayed. Some role for featured individuals in the selection of content can minimise concerns here, such as in the Save the Children campaign (2014), discussed below, where Syrian teenagers in refugee camps took and selected the images of themselves employed by the campaign.

The third level of mediation concerns the distribution of content by news outlets, NGOs, or publishers, and within formal education. There are two aspects to this process, the scale and nature of distribution, and how content is featured. This stage of mediation can rarely be removed if materials are to reach large numbers of people. The opportunity offered here is double-edged, as this process can both amplify the voices of individuals facing poverty globally and radically distort them. Beyond ability to reach large numbers of people, mediators at this stage may have significant expertise in successfully communicating messages. However, commercial pressures facing news outlets and publishers, and NGOs operating with a charitable model of what action global poverty requires of the affluent, mean that this expertise may not always be applied in a manner conducive to motivating political action, as these organisations have other goals. An additional level of complexity occurs at this stage in the selection of materials employed within formal education. In the case of works of literature, for example, not only are works rejected or selected at the editorial stage, they are then selected or rejected in determining curriculums. Finally, the behaviour of individual educators will have a significant effect on how works are interpreted and received. I discuss the complexities facing different organisations at this level of mediation below. At this stage I note that the inclusion of individuals facing poverty globally, in creating charters concerning how content is used by NGOs, or in determining the content of curriculums, can help ensure they are portrayed in a sensitive manner.

This section has argued that although dialogue offers a number of advantages for motivating political action to address global poverty, in practice, the use of representations and the presence of mediators will remain part of sentimental education for the foreseeable future. Therefore, dialogue ought to operate as an ideal rather than a requirement and mediation proceed in a sensitive manner. At a general level, sensitive processes of mediation will not obscure the voices of individuals facing poverty globally, and present these individuals as capable agents. Here, Gould's requirement of deference to those in need $(2007$, p. 157) in determining appropriate courses of 
action ought to be extended to allow these individuals to take the lead in how they feature in materials employed in processes of sentimental education. However, relatively few concrete conclusions regarding what sensitive mediation entails can be drawn at this level of generality, as mediation encompasses a number of different processes which entail different things at different sites where sentimental education occurs. The two main sites where sentimental education operates, discussed by Rorty and Nussbaum, are journalism and formal education. Woods (2012) has also highlighted the role of fundraising campaigns by NGOs working to address global poverty. The international trade union movement offers a further site where a dialogical model of sentimental education can occur (Gould 2007). In the final section of this article I demonstrate what the account of sentimental education developed here entails in practice at these four sites, highlighting incipient cases of cosmopolitan political sentimental education and offering further practical recommendations. The cases discussed here serve to substantiate the theoretical account I have outlined, demonstrating not only that the account offered is both intuitively plausible and practically feasible, but that it is a reality in action.

\section{Section Three: Political Sentimental Education in Practice}

\section{Journalism}

Journalism offers a unique opportunity as a means of sentimental education as it regularly reaches large numbers of people, including those with relatively little concern for the lives of distant others. However, depictions of individuals facing global poverty encountered in journalism are typically fleeting, and commercial pressures shape journalistic content. This can lead to sensationalised depictions, and a focus on extremes (Nussbaum 2001, p. 434). Despite this, there are some notable examples of online and print journalism cutting out the first stage of mediation by featuring content created by individuals facing poverty globally in their development reporting, and even creating forums for transnational dialogue. Here, I will discuss two such examples: the Guardian newspaper's Katine project website (The Guardian 2009) and the Panos Network (2017).

The Guardian's Katine project followed the progress of one village in Uganda that featured in a three-year development project by the Nairobi-based NGO Amref Health Africa. The Guardian followed the progress of the project over a threeyear period, and then returned in 2015 to solicit opinions from villagers and assess results. The project featured in the Guardian's standard print and online journalism but also had its own website allowing for interaction with the villagers, and featuring detailed content created by the inhabitants of Katine (Collender 2014; The Guardian 2009). Although the project itself served in part as a fund-raising exercise, the detailed and highly specific coverage, and its interactive nature offer an excellent example of the kind of journalism conducive to motivating informed political action to address poverty globally. As the reporting was highly specific to a particular location and occurred over a long time period, it offered a nuanced and accurate picture conducive to motivating effective action. For example, the website included 
a detailed interactive map of the village featuring interactive videos created by villagers (Collender 2014). This picture was contextualised through further reporting, situating Katine in a broader political context. The project also served to create the interactive ties with particular distant others recommended above, presenting these individuals in a manner that foregrounded their capacity for agency. The villagers were able to tell their own stories through the use of videos and photo diaries, and in actual dialogue via webchats. Although this style of reporting has a relatively narrow readership at present, the success of the Katine website shows that such journalism is both possible and commercially viable.

The Panos Network is a media network based in the global South that offers a platform for individuals and communities facing poverty to communicate their own development agendas, and what action (if any) they require from others. The Network also works to inform communities facing poverty concerning broader political and economic factors involved in global poverty, and to encourage informed debate over courses of action (Panos Network 2017). This Network, and similar organisations, can serve to combat media portrayals of individuals facing poverty as passive victims by amplifying the voices of these individuals. Where individuals facing global poverty communicate their own development agendas to the globally affluent, this presents them as active agents, and can help inform effective political solutions-especially where there is an emphasis on the political causes of global poverty, as in the case of the Panos Network (2017). By operating in this manner, the Panos Network also offers an example of how communities affected by global poverty can exercise a greater degree of control over the third level of mediation, the distribution of content.

\section{NGO Practices}

The materials employed by NGOs working to address global poverty represent a potentially fertile site for sentimental education, as NGOs are often trusted brands with advocacy that reaches large numbers of people. However, short-term fundraising goals play a significant role in shaping the content of NGOs promotional materials, with depictions of individuals facing global poverty often focusing on their suffering and neediness in order to motivate immediate donations (Woods 2012). Encounters with NGO fund-raising materials are also typically fleeting, leading to a greater reliance on the use of images and posing an obstacle to contextualising these images in any depth. NGOs also bear a significant share of the blame for public perceptions of addressing global poverty as a primarily charitable enterprise, requiring financial donations and little else (Kirk 2012).

Whether images of suffering offer a particularly effective means of motivating short-term donations, is unclear, but, insofar as this is the case (Slovic 2007; Jenni and Lowenstein 1997), there may be more justification for these images being employed here than at alternative sites. This is especially so, as both charitable donations to address immediate need and political reform to target the structural causes of global poverty are likely to be required for the foreseeable future. However, the use of images poses greater difficulties in portraying individuals facing poverty in 
a manner respectful of their agency than alternative mediums, as individuals featured in images have no words, which renders dialogue impossible and can serve to obscure a capacity for rational agency. As Woods notes, "we conventionally think of language as emblematic of the distinctive human capacity for rational communication' (Woods 2012, p. 41). To ensure that fund-raising images do not unnecessarily obscure agency, images ought to be contextualised and accompanied by text or audio allowing those depicted to speak, where possible. As this may not always be practically feasible, allowing individuals depicted to create their own images, or to play a role in the second stage of mediation (the editorial process) can help ensure that appropriate images are used. Publicising this involvement can further contextualise these images and increase perceptions of those involved as capable agents, closer approximating the dialogic model outlined above. An example of this strategy is the Save the Children (2014) campaign which featured teenagers in a Syrian refugee camp creating and editing their own photo portraits (a process which the campaign publicised).

Oxfam's programme of Global Citizenship Education offers an excellent example of an NGO closely approximating the model of political sentimental education I have defended. This programme operates in schools to give pupils a deeper understanding of global issues, and encourages children to see themselves as part of a global community with political responsibilities to fellow 'global citizens' (Oxfam 2015a). Oxfam's Global Citizenship Education aims to achieve long-term attitudinal change by encouraging empathy for distant others, as in the traditional model of sentimental education; however, it also works to highlight the causal complexity of global poverty, and presents individuals facing poverty and other hardships in an active role, foregrounding their agency. An example of the latter, is the degree of emphasis placed on how individuals facing global poverty are fighting for their rights (Oxfam 2015a). The programme further emphasises the equal status and agency of distant others by framing encounters with children in less affluent countries as exchanges with 'fellow students' and facilitating interaction; for example, advising teachers to 'exchange and perform poetry on a particular local-global issue with other schools locally, nationally and internationally’ (Oxfam 2015b, p. 3).

\section{Formal Education}

Formal education is perhaps the most discussed site of sentimental education and the focus of Nussbaum's account (2001, pp. 425-433). It has a number of significant advantages, as it reaches large numbers of people, occurs over a long time period, and offers an opportunity for a co-ordinated programme to be implemented. Formal education also typically faces less commercial pressures dictating content than alternative sites (Nussbaum 2001, p. 434), and presents a unique opportunity for materials depicting the lives of distant others to be contextualised and interrogated. However, this opportunity is double-edged as the critical focus relies on the presence of educators, who add a significant degree of third-level mediation to these encounters. As this area has already been widely discussed, and Oxfam's programme of Global Citizenship Education, addressed above, offers an example of good practice in this 
area, I will keep the discussion relatively brief. Attention to the political causes of poverty globally, alongside actual dialogue (where possible), and greater use of accounts authored by individuals from communities affected by poverty, to allow for second-order inclusion in dialogue (Cabrera 2010), are all to be recommended here. School twinning and pen pal schemes, taking advantage of modern communication technologies, offer strategies through which formal education can bypass the first stage of mediation and incorporate greater opportunities for actual dialogue between students in more affluent countries and those affected by poverty globally. In order to ensure that materials authored by individuals from communities affected by poverty globally are approached in a sensitive manner in the classroom, representatives from these communities ought to be included at the third level of mediation-determining how these materials are featured. This strategy has been employed elsewhere to ensure that Aboriginal people and Torres Strait Islanders are depicted appropriately in the Australian curriculum (Clifford and Montgomery 2017; Education Services Australia 2017).

\section{Trade Unions}

Trade unions feature in Carol Gould's account of transnational solidarity movements (2014, p. 125), but otherwise remain a little discussed site for sentimental education. Rather than distributing representations of distant others in media or art, trade unions offer an opportunity for transnational dialogue to occur in practice, bypassing all three stages of mediation discussed above. Trade unions also have distinct advantages for political sentimental education as they are underpinned by notions of reciprocity and equality, operating to realise common goals, with individuals participating in union activity conceptualised as workers. Accordingly, transnational union activity engages with distant others in a manner that foregrounds their capacity for agency, providing an ideal forum for the dialogic model of sentimental education developed here. Union activity is also inherently political, as it engages in processes of collective bargaining and aims to reform institutions.

However, unions may struggle to reach large numbers of people, as union membership is fairly low in some relatively affluent countries; for example, $24.7 \%$ of UK workers are members of a union (UK Government 2016), and unions play a comparatively minor political role in others, such as the United States. Unions in more affluent countries and less affluent countries may also address very different constituencies and concerns. Unions also face challenges as a means by which to encourage affective connections to individuals facing poverty globally, as they can struggle to include the very poorest, as many of these individuals work in the informal economy, as domestic workers, or subsistence farmers.

Addressing the latter concern is a priority if unions are to offer an effective means by which to encourage affective ties with individuals facing poverty globally. However, progress is already being made in this area, with unions being formed in countries with high instances of global poverty in areas of the economy that were not previously recognised by labour unions, and employing some of the poorest individuals. These are involved in the international trade union movement, and able 
to reach the attention of larger numbers of people through their own online presences and the traditional media. The Nepal Independent Domestic Workers' Union (NIDWU) is an excellent example of an internationally active union that offers support to some of the poorer member of Nepali society and operates in an area of the economy not previously recognised by union activity (WIEGO 2017). Further examples are the Indian union of waste pickers, Kagad Kach Patra Kaghtakari Panchayat (KKPKP 2017), which has unionised some of the poorest members of Indian society and received a significant amount of media attention worldwide (Carr 2014), and Brazil's Landless Workers Movement, which has successfully included subsistence farmers and agricultural day labourers into union activity (Gould 2014, p. 125). In order to overcome the former concern, unions need to have a broad media presence that target non-members. ITUC Africa (2017) offers an excellent example of this, with a website (2017) featuring content created by union members, including a 'Workers Voice' section with a number of in-depth video and audio interviews, in English and French, aimed at encouraging non-members to actively participate in the specific campaigns the union is involved in.

\section{Conclusion}

This article has developed an account of sentimental education suitable for motivating support for political action to address global poverty. The argument proceeded in three stages. Section one outlined the traditional model of sentimental education, and argued that it faces two key shortcomings as a means to motivate support for political strategies to address global poverty. First, it presents individuals facing poverty globally in a manner that obscures their capacity for agency. Second, this model leads to affective connections with distant others that are highly abstract in nature.

Drawing on the arguments advanced in section one, section two developed an alternative dialogic model of sentimental education. As dialogue may not always be possible in practice, it was suggested dialogue ought to operate as a guiding ideal rather than a strict requirement. I then argued that processes of dialogue will typically be mediated in practice, through the actions of third parties, such as journalists or NGOs, and offered an account of how mediation can proceed without obstructing dialogue.

Section three applied the model of sentimental education developed in this article to four sites: (i) the media, (ii) NGO practices, (iii) formal education, and (vi) the international trade union movement, and highlighted instances of good practice. These examples demonstrate that the account offered here is not only practically feasible, it is a reality in action.

Open Access This article is licensed under a Creative Commons Attribution 4.0 International License, which permits use, sharing, adaptation, distribution and reproduction in any medium or format, as long as you give appropriate credit to the original author(s) and the source, provide a link to the Creative Commons licence, and indicate if changes were made. The images or other third party material in this article are included in the article's Creative Commons licence, unless indicated otherwise in a credit line to the material. If material is not included in the article's Creative Commons licence and your intended use is not permitted by statutory regulation or exceeds the permitted use, you will need to obtain permission 
directly from the copyright holder. To view a copy of this licence, visit http://creativecommons.org/licen ses/by/4.0/.

\section{References}

Bartky, Sandra. 2002. Sympathy and Solidarity and Other Essays. Lanham, MD: Rowman \& Littlefield.

Brehm, Jack-Williams. 1966. A Theory of Psychological Reactance. New York: Academic Press.

Bufacchi, Vittorio. 2005. Motivating Justice. Contemporary Political Theory 4(1): 25-41.

Cabrera, Luis. 2010. The Practice of Global Citizenship. Cambridge: CUP.

Carr, Carlin. 2014. Untouchable to Indispensable: The Dalit Women Revolutionising Waste in India. https://www.theguardian.com/global-development-professionals-network/2014/jul/01/india-waste -picking-women-waste-cities-urban. Accessed 6 May 2017.

Clifford, Valerie, and Catherine Montgomery. 2017. Designing an Internationalised Curriculum for Higher Education: Embracing the Local and the Global Citizen. Higher Education Research \& Development 1(1): 1-15.

Collender, Guy. 2014. Using New Media to Report Development: The Guardian's Experiences in Katine, Uganda. http://www.lidc.org.uk/news/using-new-media-report-development-guard ian\%E2\%80\%99s-experiences-katine-uganda. Accessed 4 May 2017.

Collier, Paul. 2007. The Bottom Billion: Why the Poorest Countries are Failing and What can be Done About it. Oxford: OUP.

Dobson, Andrew. 2006. Thick Cosmopolitanism. Political Studies 54(1): 165-184.

Education Services Australia. 2017. http://www.australiancurriculum.edu.au/crosscurriculumpriorities/ aboriginal-and-torres-strait-islander-histories-and-cultures/overview. Accessed 11 May 2017.

Erskine, Toni. 2008. Embedded Cosmopolitanism: Duties to Strangers and Enemies in a World of 'Dislocated Communities'. Oxford: OUP.

Greene, Joshua, R.Brian Sommerville, Leigh Nystrom, John Darley, and Jonathan Cohen. 2001. An fMRI Investigation of Emotional Engagement in Moral Judgment. Science 293(14): 2105-2108.

Gould, Carol. 2007. Transnational Solidarities. Journal of Social Philosophy 38(1): 148-164.

Gould, Carol. 2014. Interactive Democracy: The Social Roots of Global Justice. Cambridge: Cambridge University Press.

Haldane, John. 2008. Recognising Humanity. Journal of Applied Philosophy 25(4): 301-313.

Hobbs, Joshua. 2019. Cosmopolitan Anger and Shame. Journal of Global Ethics. https://doi. org/10.1080/17449626.2019.1687567.

ITU. 2015. ICT Facts and Figures. https://www.itu.int/en/ITU-D/Statistics/Documents/facts/ICTFactsFi gures2015.pdf. Accessed 08 May 2017.

ITUC-Africa. 2017. https://www.ituc-africa.org/. Accessed 1 May 2017.

Izard, Carroll, and Beier Ackerman. 2000. Motivational Organisational, and Regulatory Functions of Discrete Emotions. In Handbook of Emotions, ed. M. Lewis and M. Haviland-Jones, 253-264. New York: Guilford.

Jenni, Karen, and George Loewenstein. 1997. Explaining the 'Identifiable Victim' Effect. Journal of Risk and Uncertainty 14(1): 235-257.

Kirk, Martin. 2012. Beyond Charity: Helping NGOs Lead a Transformative New Public Discourse on Global Poverty and Social Justice. Ethics \& International Affairs 26(2): 245-263.

KKPKP. 2017. http://www.kkpkp-pune.org/. Accessed 2 May 2017.

Kuper, Andrew. 2002. More than Charity: Cosmopolitan Alternatives to the Singer Solution. Ethics \& International Affairs 16(1): 107-120.

Langlois, Antony. 2008. Charity and Justice in Global Poverty Relief. Australian Journal of Political Science 43(4): 685-698.

Lawford-Smith, Holly. 2010. Feasibility Constraints and the Cosmopolitan Vision. In Questioning Cosmopolitanism, ed. S. Van Hooft and W. Vandekerckhove, 134-150. London: Springer.

Lenard, Patti. 2012. Creating Cosmopolitans. Critical Review of International Social and Political Philosophy 15(1): 613-660.

Lichtenberg, Judith. 2014. Distant Strangers: Ethics, Psychology, and Global Poverty. Cambridge: CUP.

Linklater, Andrew. 2007. Distant Suffering and Cosmopolitan Obligations. International Politics 44(1): $19-36$. 
Long, Graham. 2009. Moral and Sentimental Cosmopolitanism. Journal of Social Philosophy 40(3): 317-342.

Nussbaum, Martha. 1996. Patriotism and Cosmopolitanism. In For Love of Country?, ed. J. Cohen, 3-17. Boston, MA: Beacon Press.

Nussbaum, Martha. 2001. Upheavals of Thought: The Intelligence of Emotions. Cambridge: CUP.

O’Neill, Onora. 2000. Bounds of Justice. Cambridge: CUP.

Oxfam. 2015a. Global Citizenship in the Classroom. http://www.oxfam.org.uk/education/global-citiz enship/global-citizenship-guides. Accessed 05 May 2017.

Oxfam. 2015b. English and Global Citizenship. http://www.oxfam.org.uk/education/global-citizenship/ global-citizenship-guides. Accessed 05 May 2017.

Panos Network. 2017. http://panosnetwork.org/. Accessed 11 May 2017.

Pogge, Thomas. 2002. World Poverty and Human Rights: Cosmopolitan Responsibilities and Reforms. Cambridge: Polity.

Real Time Statistics Project. 2017. http://www.internetlivestats.com/internet-users/india/. Accessed 05 May 2017.

Rorty, Richard. 1991. Essays on Heidegger and Others: Philosophical Papers, vol. 2. Cambridge: CUP.

Rorty, Richard. 1998. Truth and Progress: Philosophical Papers, vol. 3. Cambridge: CUP.

Save the Children. 2014. http://www.savethechildren.org.uk/2014-11/syrian-teenagers-work-top-magnu m-iphone-photographer-produce-their-own-portrait-life-refugee. Accessed 15 May 2017.

Schwarzenbach, Sybil. 2009. On Civic Friendship: Including Women in the State. New York: Columbia University Press.

Singer, Peter. 1972. Famine, Affluence, and Morality. Philosophy \& Public Affairs 1(3): 229-243.

Singer, Peter. 2010. The Life You Can Save: How to Do Your Part to End World Poverty. London: Picador.

Slovic, Paul. 2007. If I Look at the Mass I will Never Act: Psychic Numbing and Genocide. Judgement and Decision Making 2(2): 79-95.

Straehle, Christine. 2010. National and Cosmopolitan Solidarity. Contemporary Political Theory 9(1): $110-120$.

The Guardian. 2009. Katine. https://www.theguardian.com/katine. Accessed 07 May 2017.

UK Government DBIS. 2016. Trade Union Membership 2015. https:/www.gov.uk/government/statistics/ trade-union-statistics-2015. Accessed 12 May 2017.

Ulas, Luke. 2017. Transforming (But Not Transcending) the State System? On Statist Cosmopolitanism. Critical Review of International Social and Political Philosophy. 20(6): 657-676.

UN. 2016. Human Development Report 2016. http://hdr.undp.org/en/2016-report. Accessed 07 May 2017.

WIEGO. 2017. Nepal Independent Domestic Workers Union. Available at: http://www.wiego.org/conte nt/nepal-independent-domestic-workers-union-nidwu. Accessed 06 May 2017.

Weinstock, Daniel. 2009. Motivating the Global Demos. Metaphilosophy 40(1): 92-108.

Woods, Kerri. 2009. Suffering, Sympathy, and (Environmental) Security: Reassessing Rorty's Contribution to Human Rights Theory. Res Publica 15(1): 53-66.

Woods, Kerri. 2012. Whither Sentiment? Compassion, Solidarity, and Disgust in Cosmopolitan Thought. Journal of Social Philosophy 43(1): 33-49.

Ypi, Lea. 2008. Statist Cosmopolitanism. Journal of Political Philosophy 1691: 48-71.

Publisher's Note Springer Nature remains neutral with regard to jurisdictional claims in published maps and institutional affiliations. 